\title{
Getting What You Pay For: Children's Use of Market Norms to Regulate Exchanges
}

\author{
Margaret Echelbarger and Susan A. Gelman \\ University of Michigan
}

\author{
Charles W. Kalish \\ University of Wisconsin
}

\begin{abstract}
Children are sensitive to a number of considerations influencing distributions of resources, including equality, equity, and reciprocity. We tested whether children use a specific type of reciprocity norm-market normsin which resources are distributed differentially based strictly on amount offered in return. In two studies, 195 children 5-10 years and 60 adults distributed stickers to friends offering same or different amounts of money. Overall, participants distributed more equally when offers were the same and more unequally when offers were different. Although sensitive to why friends offered different amounts of money, children increasingly incorporated market norms into their distributions with age, as the oldest children and adults distributed more to those offering more, irrespective of the reasons provided.
\end{abstract}

People make decisions about allocating resources to other people in many contexts. However, it is not always clear how those allocations should be made. The developmental literature has focused on children's developing conceptions of different kinds of "fair" allocation strategies - equality and equity. Equality is the relatively simple principle that everyone gets the same. Consider, for example, a situation where you have been tasked with distributing four new pens to two people. If using an equality norm, you would distribute two pens to each person. Equity is a more complex construction of fairness involving assessments of deservingness (e.g., how much a person contributes should determine the outcomes they experience; Carrell \& Dittrich, 1978). Perhaps, one of the potential recipients helped you complete another task earlier in the day, an equitable distribution gives more to the helpful person. Alternatively, one person may have many pens and the other none; an equitable distribution, in this case, gives more to the needy person. A significant body of empirical research has

We thank the children, their families, and the adults who participated in this research. We are especially grateful to the Ann Arbor Hands-On Museum and the University of Michigan Museum of Natural History for providing lab space for this research as part of the University of Michigan Living Lab program. We also thank Shahrooz Ali, Diarra Brooks, Leah Butler, Ergest Isak, Avery Katz, Melissa Kreutz, Sarah Snay, Zaria Starfeldt, Anna Wendorf, and Gizem Yagci for their help with data collection and processing. Lastly, we thank Selin Gülgöz for providing access to the stimuli.

Correspondence concerning this article should be addressed to Margaret Echelbarger, Department of Psychology, University of Michigan, 530 Church Street, Ann Arbor, MI 48109. Electronic mail may be sent to echelbar@umich.edu. explored which kinds of equity considerations children attend to and when (e.g., Baumard, Mascaro, \& Chevallier, 2012; Elenbaas \& Killen, 2016; Elenbaas, Rizzo, Cooley, \& Killen, 2016; Hamann, Bender, \& Tomasello, 2014; Kanngiesser \& Warneken, 2012; Kenward \& Dahl, 2011; Rizzo, Elenbaas, Cooley, \& Killen, 2016).

In this paper, we consider a third norm of particular cultural and practical significance: market exchange. What if people are buying and selling pens? In a market exchange the allocation problem is establishing a price: how to maximize returns (for both buyer and seller). Although equity might require that a more deserving person get more even if they cannot pay more, the principles of market exchange do not. In this sense, market norms can be construed as qualitatively distinct from equality and equity norms, which have more of a social or personal element (Heyman \& Ariely, 2004). To extend the example provided earlier, of distributing four pens to two people, a market exchange would entail allocating the pens in such a way as to maximize the amount of resources received in return. The "right" thing to do in a market is to get the best price for your goods. Distributing this way may not produce an equal outcome, or an equitable outcome; however, it is appropriate under market norms.

As noted earlier, children's attention to equality and equity tend to be studied in the context of

(C) 2018 Society for Research in Child Development All rights reserved. 0009-3920/2019/9006-0016 DOI: $10.1111 /$ cdev. 13088 
fairness, to which children show a strong commitment. In many contexts that have been studied, children's "fair" distributions tend to be equal, particularly in third-party distribution contexts (i.e., when the participants themselves are not recipients). In third-party contexts, for example, children as young as 6-8 years are averse to unequal distributions and will even throw away odd items to preserve equality (Shaw \& Olson, 2012). Attention to equality may be present in infancy (Sloane, Baillargeon, \& Premack, 2012), which suggests that it emerges early - even before children can physically engage in third-party distributions.

Although often motivated by equality, children are not wholly committed to it in all contexts. For example, children as young as 3.5 years help protagonists preferentially distribute to puppet friends and family members compared with strangers in third-party contexts (Olson \& Spelke, 2008). In a shift toward equity, children as young as 5-6 years distribute unequally to rectify third-party ingroup inequalities (e.g., Elenbaas et al., 2016). Preschool children also distribute differently depending on their preference for a recipient (Chernyak \& Sobel, 2016); children of this age will also take merit and past behavior into account when deciding how to distribute items (Baumard et al., 2012). For example, when resources are less plentiful, 4.5-year-olds give more to helpful versus unhelpful recipients (Kenward \& Dahl, 2011). Thus, young children will deviate from equal distributions to perform equitable distributions, which consider a potential recipient's deservedness along various dimensions including need, effort, time, and/or status (see Deutsch, 1975 for an early review of different dimensions along which just distributions can be made). Overall, with increasing age, children display an increasing departure from equal distributions based on justified equity concerns (e.g., merit, need) from preschool age through at least middle childhood (Schmidt, Svetlova, Johe, \& Tomasello, 2016).

Although prior work has extensively explored how equality and equity concerns guide children's distributions, much less is understood about the influence of market norms. Though children lack adult-like understanding of market principles, possibly due, in part, to parents' reluctance to discuss personal financial matters in the home (Romo, 2011), children regularly engage in exchange-type behaviors (e.g., trading toys, food) wherein the goal is to maximize value. For example, children at lunch may seek out more desirable snacks and look to friends to trade. Market norms reflect principles (e.g., value, price) for resource distributions that people, particularly those participating in a capitalistic economy, grapple with on a day-to-day basis. Within this type of economy, the receipt of resources and goods is linked to the amount someone offers in exchange rather than linked to desert or need (Fiske, 1991).

Market norms may be understood as a specific form of reciprocity. Reciprocity involves giving resources in the expectation (or in response to) receipt of resources: You give to me so I give to you. A significant body of research has explored children's sensitivity to reciprocity considerations. Prior work in this area shows that children as young as 3 years engage in direct reciprocity via first-party (Dunfield, Kuhlmeier, \& Murphy, 2013) and third-party tasks (Olson \& Spelke, 2008; see House, Henrich, Sarnecka, \& Silk, 2013, for overview of the development of contingent reciprocation in children 3-7.5 years). For example, by 3.5 years, children track past behaviors to reason about who should receive later resources (Olson \& Spelke, 2008), and by age 5 years, they share more with partners who may reciprocate in the future versus not (Sebastián-Enesco \& Warneken, 2015).

The kind of reciprocity addressed in prior research is a more general, informal form than that involved in market norms. We suggest that market norms are a specific kind of reciprocity involving direct quid pro quo. Informal reciprocity involves a loose account of balance in the long run. For example, the expectation that a gift or favor may someday be returned, without explicit understanding of the amount or timing, is informal reciprocity. Indeed, it is a violation of informal reciprocity to demand or offer direct quid pro quo. One cannot offer to pay (or otherwise assign a specific value) for a meal at a friend's house (Tetlock, 2003). Nor ought one to expect that the value received in reciprocation matches the value given (the meal you invite me to may not be equal in value to the labor I expended helping you move). It is the specific accounting character of tracking the particular value of goods during a single exchange that distinguishes market exchanges from informal reciprocity.

We operationalize market exchanges as those involving money. How do children understand exchanging goods for money? Clearly monetary exchanges are not equal - everybody who walks in to a store does not walk out with the same goods. Monetary exchanges are also not based on equity as traditionally conceived, because the amount of money offered in a market exchange need not 
rectify inequalities or reward those who work harder or are more deserving. For example, a person may be highly deserving, but if they do not provide the asking price, then they will not have access to goods (Rizzo \& Killen, 2016). In contrast, in monetary exchanges, people will generally receive goods in proportion to the amount they offer. This relation is especially reliable in fixedprice transactions (e.g., shopping) that characterize most monetary exchanges for the population involved in the current study. Neither norms of equality nor norms of equity capture adult expectations for monetary exchanges, strictly conceived.

Finally, market exchanges are not equivalent to other forms of reciprocity. Whereas reciprocity may entail consideration of past or future reciprocation, market exchanges can be based on singular interactions with those one has not met before and is unlikely to meet again in the future. Although prior research indicates that young children consider reciprocity as it rests on enduring (or at least repeated) personal relationships, it is unclear whether children's judgments involve one-shot market exchanges. Whereas reciprocity may entail a general sense of "do me a favor, and I'll do you a favor," market exchanges entail more precise expectations about the amount of timing of exchanges.

Though prior research exploring reciprocity in children tests whether they are sensitive to past and future behaviors when distributing resources, it is unclear how children reason about market exchanges in this stricter sense. Understanding core market principles, such as the role of supply and demand in determining a price, involves extended development (see Siegler \& Thompson, 1998). However, the basic intuition that it is acceptable to distribute more items to one who offers higher payments may develop early, at least for children in modern Western societies who grow up immersed in a market economy - an aspect of reciprocity that has yet, to our knowledge, to be explored. More generally, it remains an open question whether and how young children apply these three norms (equality, equity, and market) in the context of monetary exchanges.

\section{Present Research}

The present research tests how 5- to 10-year-old children's third-party distributions are affected by money offers, as prior work in the areas of fairness and merit understanding suggests that changes should be observed across this age range. Attention to equality has been observed in the youngest age within this range (e.g., Shaw \& Olson, 2012), whereas attention to equity expands in scope. Thus, for example, by preschool age (3-4 years), children consider merit when determining how to distribute items - that is, children allocate based on individual contributions (Baumard et al., 2012). In contrast, by 10-11 years, children act on a more nuanced understanding of merit (and deservedness) to rectify social inequalities - that is, older children seek to correct disparities across groups (Elenbaas et al., 2016). We, therefore, expected adherence to increasingly shift toward incorporating equity concerns across the age range. In addition, the youngest children within this age range have been shown to track cooperative behaviors and engage in contingent reciprocation (Sebastián-Enesco \& Warneken, 2015). For these reasons, it is of particular interest to determine how children would reason about market norms in the context of these developmental changes.

Across two studies, children (and adults as a comparison group) help a Giver distribute extra stickers. Using a third-party design allowed us to present the relationships among the Giver and Friends neutrally, thus providing a better test of market norms (which should apply even among strangers), and eliminating the child's own stake in the distributions. In Study 1, participants help a Giver distribute extra stickers among the Giver and two friends. In Study 2, participants help a Giver distribute extra stickers between two friends only. In both studies, friends make offers to the Giver for the extra stickers, offering no money (allowing for comparisons to previous literature), equal amounts of money, or different amounts of money. When offers are different, the reasons vary: (a) one friend simply offers more money (no reason provided), (b) one friend refuses to pay despite having funds available, or (c) one friend wants to pay, but lacks available funds. We include these scenarios to test, in a market exchange context, whether differences in monetary offers are the only factor that matters or whether children factor in equity concerns: Do you get what you pay for, or what you deserve?

\section{Predictions}

If guided strictly by equality norms, then children will distribute stickers equally irrespective of the offers. If guided by equity, then children will distribute stickers equally when offers are the same (i.e., when no money is involved, and when equal amounts of money are offered). Equity norms would also predict that when offers are different 
and no explanation for the difference is provided, or when one friend is able but refuses to pay, children will distribute unequally in favor of the friend offering more. However, when someone is willing but unable to pay, equity would favor either an equal distribution (both participants are deserving) or an unequal distribution in favor of the person who is unable to pay (to rectify an inequality). Finally, if guided by market norms, children will strictly distribute stickers based on the payment offered. That is, when offers are the same, children will distribute equally, and when offers are different, children will distribute unequally in favor of the friend offering more. Thus, trials where one friend is willing but unable to pay provide the clearest test of whether children adhere to equity versus market norms (i.e., equity entails equal distributions or favoring the friend willing but unable to pay; market entails favoring the friend offering more money).

Finally, we predict that the degree to which children depart from equality will differ by age. That is, younger children (5-6 years) are predicted to display a stronger commitment to equal distributions than older children (9-10 years) and adults. Younger children may also be more influenced by equity (ability to pay) than older children and adults, who have more experience with fixed prices (e.g., the grocery store does not care how rich you are). Thus, we predict that principles for all three types of exchanges will be available from an early age, but the degree to which children appeal to equity and to market considerations will increase with age (see Rizzo \& Killen, 2016).

\section{Study 1}

\section{Method}

\section{Participants}

Participants included 76 children between the ages of 5 and 10 years, subdivided into three age groups: 5-6 years $(n=27, M=5.94, S D=.56,15$ female), 7-8 years $(n=24, M=7.71, S D=.49,15$ female), and $9-10$ years $(n=25, M=9.70, S D=.48$, 12 females). Twenty-five adults $(M=19.10$, $S D=.93,16$ female) also participated. Prior to analyzing the data, an additional 13 children were excluded for the following reasons: three due to experimenter error (e.g., recording errors), four due to observing other participants complete the task, four due to parental or friend interference, and two for not completing the task. Only one adult was excluded due to experimenter error. Children were recruited and tested in lab spaces at two local museums between September 2015 and January 2016. We did not collect data on race, ethnicity, nor socioeconomic status; however, one museum required an entrance fee, whereas the other did not. Adults were recruited via a university psychology subject pool between October 2015 and November 2015. Children received a thank-you gift for participating, and adults received course credit.

\section{Materials}

Materials included laminated squares depicting one of five shapes: star, circle, triangle, crescent, or hexagon. The laminated squares with shapes represented the stickers participants were asked to distribute on behalf of the Giver. Depending on the trial, there were four or five laminated squares of each shape, and shapes within a trial were all colored the same, with no color repeated across trials. Shapes were placed in collection bowls for Friends and/or on top of a plastic bag for the Giver, allowing us to more clearly distinguish Friends from the Giver. Stickers for the Giver were placed on a plastic bag, as it is more plausible that extra stickers (which the Giver had brought) would be contained in a bag rather than in a bowl prior to distributing.

\section{Design}

Participants heard third-party vignettes describing situations where friends offered no money (no money), equal amounts of money (one quarter each; equal money), or different amounts of money (see Table 1 for sample vignettes of each type). The following different offers were made: (a) more/less: one friend offers two quarters, one friend offers one quarter, (b) refusal: one friend offers one quarter, one friend refuses to offer the one quarter they have available, and (c) inability: one friend offers one quarter, one friend offers zero quarters due to being unable to pay (i.e., having no quarters). For each scenario, there were two trials-one requiring the distribution of four stickers, and one requiring the distribution of five stickers. Thus, participants heard 10 vignettes total (see Table 2 for complete design).

The 10 vignettes were presented in three blocks: no-money vignettes, money vignettes involving the distribution of four stickers (even), and money vignettes involving the distribution of five stickers (odd). The no-money block was always presented first to avoid potential effects of money influencing 
Table 1

Sample Vignettes Heard by Participants

\begin{tabular}{|c|c|c|}
\hline Offer type & Vignette type & Vignette \\
\hline Same & No money & $\begin{array}{l}\text { Sally is at the park with her friends Bernice and Hazel. Sally has some extra stickers she doesn't need. Bernice says, } \\
\text { "Sally, can I have some stickers?" and Hazel says, "Sally, can I have some stickers?" }\end{array}$ \\
\hline Same & Equal money & $\begin{array}{l}\text { Lucy is at the park with her friends Olive and Barbara. Lucy has some extra stickers she doesn't need. Olive says, } \\
\text { "Lucy, can I have some stickers? I'll pay you } 1 \text { quarter for some stickers," and Barbara says, "Lucy, can I have } \\
\text { some stickers? I'll pay you } 1 \text { quarter for some stickers." }\end{array}$ \\
\hline Different & More/less & $\begin{array}{l}\text { Georgette is at the park with her friends Alice and Cecelia. Georgette has some extra stickers she doesn't need. } \\
\text { Alice says, "Georgette, can I have some stickers? I'll pay you } 1 \text { quarter for some stickers," and Cecelia says, } \\
\text { "Georgette, can I have some stickers? I'll pay you } 2 \text { quarters for some stickers." }\end{array}$ \\
\hline Different & Refusal & $\begin{array}{l}\text { Colleen is at the park with her friends Beatrice and Myrtle. Colleen has some extra stickers she doesn't need. } \\
\text { Beatrice says, "Colleen, can I have some stickers? I have } 1 \text { quarter, but I don't want to pay," and Myrtle says, } \\
\text { "Colleen, can I have some stickers? I'll pay you } 1 \text { quarter for some stickers." }\end{array}$ \\
\hline Different & Inability & $\begin{array}{l}\text { Kelly is at the park with her friends Sue and Ida. Kelly has some extra stickers she doesn't need. Sue says, "Kelly, } \\
\text { can I have some stickers? I'll pay you } 1 \text { quarter for some stickers," and Ida says, "Kelly, can I have some stickers? } \\
\text { I want to pay, but I don't have a quarter." }\end{array}$ \\
\hline
\end{tabular}

Note. Vignettes gender-matched to child. Girls heard about friends with female names (included above), boys heard about friends with male names. After each vignette, participants' distribution options were reiterated.

Table 2

Offer and Vignette Types in Studies 1 and 2

\begin{tabular}{|c|c|c|c|}
\hline Offer type & $\begin{array}{l}\text { Vignette } \\
\text { type }\end{array}$ & $\begin{array}{l}\text { Friend A's } \\
\text { offer }\end{array}$ & Friend B's offer \\
\hline \multirow[t]{2}{*}{ Same } & No money & 0 & 0 \\
\hline & Equal money & 1 quarter & 1 quarter \\
\hline \multirow[t]{3}{*}{ Different } & More/less & 2 quarters & 1 quarter \\
\hline & Refusal & 1 quarter & $\begin{array}{l}0 \text { (though } 1 \text { quarter is } \\
\text { visible in B's bag) }\end{array}$ \\
\hline & Inability & 1 quarter & 0 \\
\hline
\end{tabular}

Note. In Study 1, participants distributed four or five stickers, depending on the block. In Study 2, participants only distributed five stickers.

participants' distributions in the absence of money, and the order of the other two blocks was randomized. The order of the vignettes within blocks was randomized and the side on which unequal offers were made was counterbalanced across participants.

\section{Procedure}

Children. Before the session began, a parent/ guardian provided written consent and the child provided oral assent. The child then worked with an experimenter individually who told them that they were going to hear some stories and answer some questions. The experimenter read 10 vignettes displayed on a computer, each depicting three characters - a Giver and two friends, gender matched to the child-and children were tasked with helping the Giver decide how to give away the Giver's extra stickers. During each vignette, children were told that the Giver could give away the extra stickers any way they wanted-they could give them to both friends or to just one friend, and they could give them all away or keep some for the Giver. The Giver was included as a possible recipient to allow for equal distributions to the Friends during the five-sticker trials. While reading the vignette, the experimenter laid out all stickers directly in front of the child, in a row. The child was then instructed to put stickers for the friends in corresponding collection bowls (situated on either side of the computer) and to put stickers for the Giver on a plastic bag (situated in front of the computer). This arrangement of collection bowls and bag mirrored the spatial relationship of the characters on the computer screen (Figure 1). The number of stickers distributed to each character was recorded. At the conclusion of the task, children were asked why they distributed stickers as they had during the last trial. Responses were gathered for exploratory purposes and are not discussed further.

Adults. Adults provided consent and completed the same task as presented to children.

\section{Results}

To test our predictions, we first tallied the number of stickers distributed to each possible recipient (Friend A, Friend B, Giver). When different offers were made, Friend $\mathrm{A}$ was defined as the friend who offered more money. When same offers were 
(a)

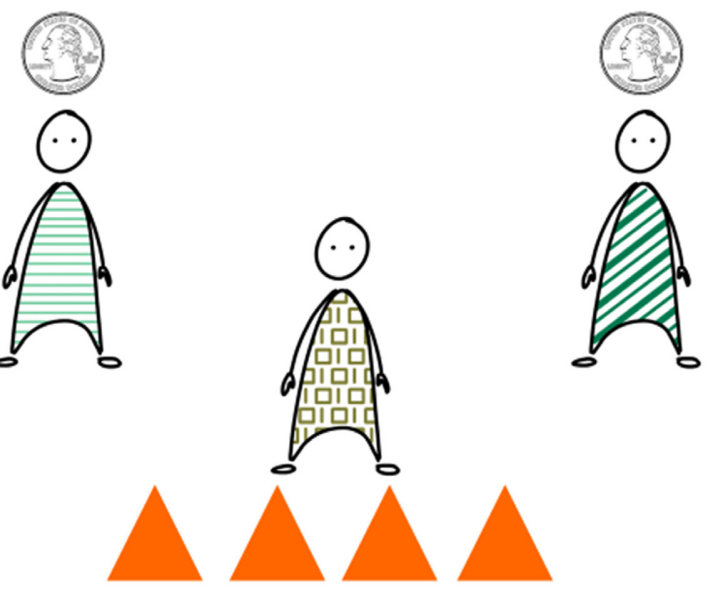

(b)
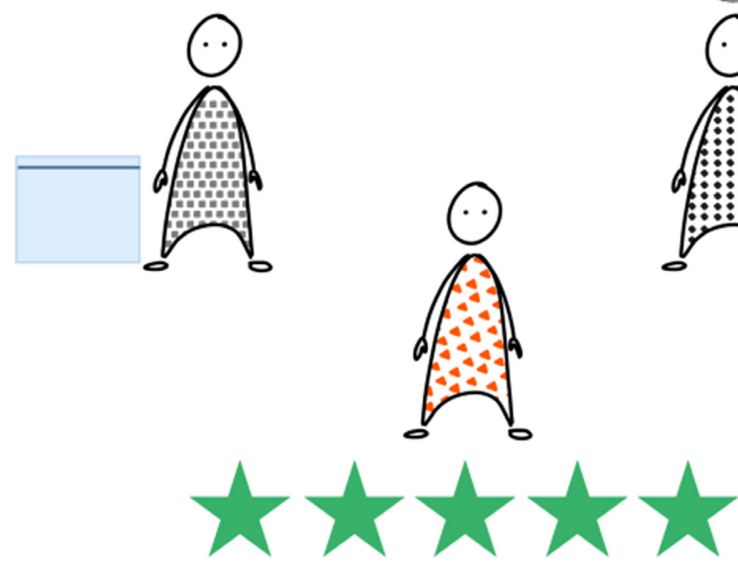

Figure 1. Sample vignettes: (a) equal money, even number of stickers; (b) inability, odd number of stickers. After hearing vignettes, participants distributed stickers matching those present on the computer screen to the recipients. [Color figure can be viewed at wileyonlinelibrary.com]

made, Friend A was simply defined as the friend on the left.

\section{Same Versus Different Offers}

We first predicted that participants would distribute stickers more equally when offers were the same: When offers were different, equity and market considerations should lead participants to distribute more stickers to friends offering more money. To test this, we collapsed across same trials (no money, equal money) and collapsed across different trials (more/less, refusal, inability), and then for same versus different trials separately, we calculated the proportion of trials for which an equal number of stickers was distributed to Friend $\mathrm{A}$ and Friend B (i.e., zero to each, one to each, or two to each). Proportions were used to permit comparison across the different numbers of trials (two same offer trials, three different offer trials). We conducted a repeated-measures analysis of variance (ANOVA) with offer type (same, different) and sticker number (even, odd) as the within-participants factors and age group (5-6, 7-8, 9-10, adults) as the between-participants factor.

As predicted, participants were more likely to distribute stickers equally during same $(.88)$ versus different (.42) trials, $F(1,97)=189.22, p<.001$, $\eta_{\mathrm{p}}^{2}=.66$. However, this effect interacted with age group, $F(3,97)=13.25, p<.001, \eta_{\mathrm{p}}^{2}=.29$. To examine the interaction, we tested the effect of offer type within each age group considered individually, setting our alpha level for post hoc comparisons of the interaction to $.0125(.05 / 4$ age groups) to account for multiple comparisons. At all age groups, participants distributed more equally when offers were the same versus different (5-6: 0.72 vs. $0.56 ; 7-8$ : 0.89 vs. 0.48 ; $9-10$ : 0.94 vs. 0.40 ; adults: 0.97 vs. 0.23 ; $p \mathrm{~s} \leq .012$ ). See Figure 2 for distributions by offer type and age group. Finally, there was a main effect of sticker number, $F(1,97)=5.89, p=.017$, $\eta_{\mathrm{p}}^{2}=.06$, indicating that participants distributed more equally between the two friends when an even number of stickers was available to give away than when an odd number of stickers was available to give away (.68 vs. .62). This result may be due to the relative ease of distributing an even versus odd number of stickers between two people. No other significant results were found.

\section{No-Money Versus Equal Money Offers}

We next tested whether participants' distributions differed during same offers when money was involved versus not involved. Testing whether this is the case serves as an important control to check that introducing money offers does not unexpectedly influence behaviors. Again, our dependent variable was the proportion of trials on which participants distributed the stickers evenly between A and B. We conducted a repeated-measures ANOVA with vignette type (no money, equal money) and sticker number (even, odd) as the within-participants factors and age group (5-6, 7-8, 9-10, adults) as the between-participants factor. We obtained only one significant effect, a main effect of age group, $F(3,97)=7.35, p<.001, \eta_{p}^{2}=.19$. Children 5-6 years distributed less equally than participants in all other age groups $(5-6: 0.72 ; 7-8: 0.89 ; 9-10$ : 0.94; adults: 0.97 ; all $p s<.01$ ). Thus, the inclusion of money in the allocation context had no bearing 


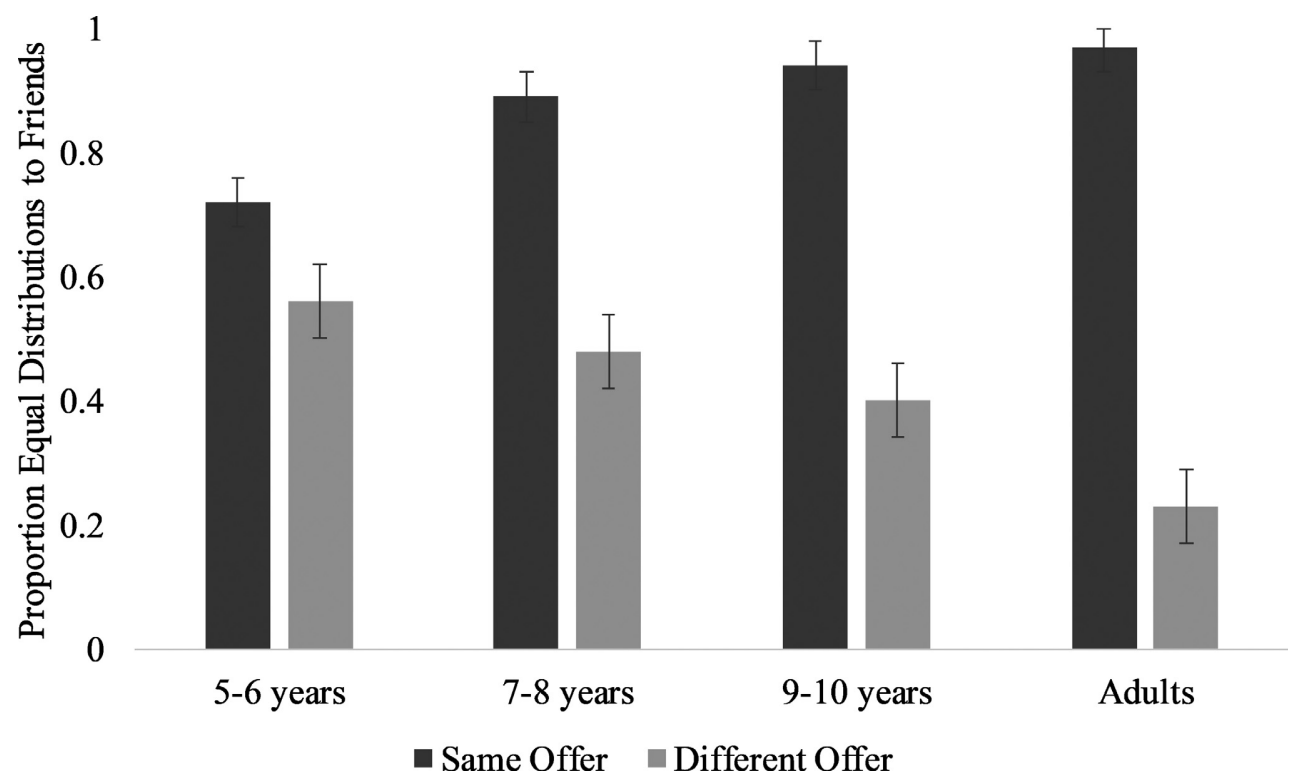

Figure 2. Proportion equal distributions to friends during Study 1.

on the likelihood of distributing equally when offers were the same.

\section{Different Offers: Market Norms Versus Equity Norms}

Turning to trials where different offers were made, we predicted that, if strictly adhering to market norms, participants would distribute more stickers to Friend A than Friend B, because Friend A was defined as the one who offered more. However, equity norms would dictate equal or more favorable distributions to the friend willing but unable to pay. To test this, we calculated a difference score - subtracting the number of stickers distributed to Friend B from the number of stickers distributed to Friend A. Positive values indicate more stickers for Friend A, whereas negative values indicate more stickers for Friend B. We conducted a repeated-measures ANOVA with vignette type (more/less, refusal, inability) and sticker number (four, five) as the within-participants factors and age group (5-6, 7-8, 9-10, adults) as the between-participants factor. This analysis yielded main effects of vignette type, $F(2,194)=15.88$, $p<.001, \eta_{\mathrm{p}_{2}}^{2}=.14$, and age group, $F(3,97)=10.10$, $p<.001, \eta_{p}^{2}=.24$. Participants distributed more stickers to Friend A during both more/less (.87) and refusal (.96) trials than during inability (.35) trials $(p s<.001)$, suggesting that participants are sensitive to the reasons for which friends offer no money. Again, setting our alpha level to .0125 to account for multiple comparisons, we found that the difference in the number of stickers distributed to Friend A versus Friend B was smaller for all groups of children than for adults (5-6: 0.35; 7-8: 0.58; 9-10: 0.75; adults: 1.23; $p \mathrm{~s}<.01$ ). See Figure 3 for distributions by vignette type and age group. No other significant results were found.

We next tested whether participants reliably distributed more stickers to the friend offering more money, testing participants' commitment to equity versus market norms. That is, we tested whether participants distributed significantly more stickers to Friend $A$ than to Friend $B$ than would be expected by chance (0). Because no effect of sticker number was found, we collapsed across this variable in this analysis (one-sample $t$-test; alpha not adjusted given independence of $t$-tests). At all age levels, participants distributed stickers to Friend A above chance during more/less (5-6: 1.30; 7-8: 1.58; 9-10: 1.84; adults: 2.24$)$ and refusal (5-6: 1.07; 7-8: 1.42; 9-10: 1.88; adults: 3.32) trials ( $p s<.02)$. However, during inability trials, only children 910 years and adults distributed stickers above chance to Friend A (5-6: -0.30; 7-8: 0.46; 9-10: 0.80; adults: 1.84; $p$ s for the latter two age groups $\leq .002)$, demonstrating that older children and adults are more likely to adhere to market norms irrespective of the reasons for which lower offers are made.

\section{Zero Offers: Market Norms Versus Equity Norms}

Finally, we considered how often participants gave a nonzero number of stickers to the friend offering less. That is, did they adopt a strategy in 


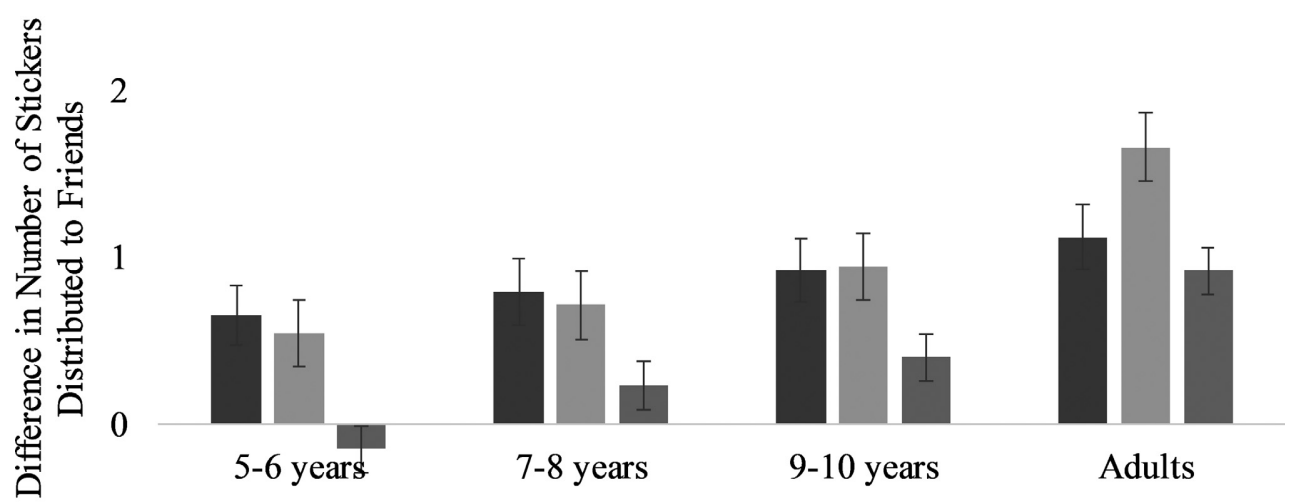

$-1$

- Pay More vs. Less $\quad$ Pay vs. Refuse to Pay $\quad$ Pay vs. Unable to Pay

Figure 3. Difference in the number of stickers distributed to friends (where positive numbers indicate a preference for the friend offering more) during Study 1.

which one who does not pay gets nothing (which would be consistent with a pure market norm), or did they give at least something to the person offering less (indicating some degree of equity)? To test this, we tallied the number of trials on which participants (by age group, collapsed across sticker number) distributed zero stickers to friends offering less money during more/less trials and no money during refusal and inability trials. This was done to test whether participants engaged in a pure-profit strategy (i.e., distributed stickers only to the friend offering more money) without concern for equity, which would predict that participants would, for example, be more likely to distribute zero stickers to the friend refusing versus willing but unable to pay. On this analysis, we found that overall participants rarely gave nothing to the friend offering less money. During more/less trials, friends offering one fewer quarter received nothing on 14 of 202 trials $(6.93 \%$ overall; $5-6: 8 / 54$ trials; $7-8: 1 / 48$ trials; 9-10: $3 / 50$ trials; adults: $2 / 50$ trials). Similar rates of zero distributions were given when the friend offering less was willing but unable to pay $(5.94 \%$ overall; 5-6: 5/54 trials; 7-8: 4/48 trials; 9-10: 1/50 trials; adults: $2 / 50$ trials). However, participants were more inclined to give nothing to the friend refusing to pay (19.31\% overall; $5-6: 8 / 54$ trials; 7 8: $11 / 48$ trials; $9-10$ : $8 / 50$ trials; adults: $12 / 50$ trials). Interestingly, participants' zero distributions did not differ by age group during any trial type, as assessed via logistic regressions where age group was entered as a categorical predictor and decision to give nothing versus at least one sticker was entered as the binary-dependent variable. These results are consistent with those from the previous analyses showing that children are sensitive to the reason for the no-money offer and suggest that children incorporate equity concerns into their distribution decisions in this market context.

\section{Discussion}

Overall, throughout the age range tested here (510 years and adults), participants tended to distribute stickers equally between friends when offers were the same, consistent with prior research showing that children adhere to an equality-distribution strategy in third-party contexts. However, participants (again, in all age groups) were more likely to distribute unequally when different offers were made. Participants distributed equally on fewer than half of the unequal trials $(42 \%)$, which is in stark contrast to the proportion of equal distributions observed when offers were the same $(88 \%)$. Thus, different offers can encourage children to depart from equality when distributing items. Interestingly, although participants in all age groups distributed more stickers to the friend who offered more money during more/less and refusal trials, only the oldest children and adults distributed more stickers to the friend offering more money during inability trials. This suggests that there is an increase with age in children's willingness to abandon equal or equitable norms for distributions and 
adhere to market norms when they conflict, a point to which we return in the General Discussion.

In Study 1, participants could have employed an equality-distribution strategy by distributing odd items to the Giver - and indeed, participants did regularly distribute items to the Giver. Because Study 1 allowed for equal distributions on each trial, it does not provide the most sensitive test of children's commitment to equal distributions, nor does it tell us how sensitive children are to the different ways in which offers can be unequal. It is, thus, an open question how children would respond if unable to distribute equally on each trial. The purpose of Study 2 was to test whether even the youngest children would more consistently depart from equality when the task did not permit equal distributions on a given trial. To test this, on every trial, participants were tasked with distributing an odd number of stickers (i.e., five; no foursticker trials included) and were unable to distribute to the Giver (i.e., they could only distribute between friends A and B). Study 2 also provides an opportunity for conceptual replication of Study 1.

\section{Study 2 \\ Method}

\section{Participants}

Participants included 119 children between the ages of 5 and 10 years, subdivided into three age groups: $5-6$ years $(n=41, M=5.95, S D=.61,20$ female), $7-8$ years $(n=42, M=7.91, S D=.58,21$ female), and $9-10$ years $(n=36, \quad M=10.03$, $S D=.55,16$ female), and 35 adults $(M=19.05$, $S D=.69,18$ female). Prior to analyzing the data, an additional three children were excluded: two due to not understanding English and one due to watching a previous participant complete the task. Only one adult was excluded due to experimenter error. Children were recruited and tested in lab spaces between June 2016 and July 2016 at the same museums where testing took place in Study 1. As in Study 1, we did not collect data on race, ethnicity, or socioeconomic status. Adults were recruited via a university psychology subject pool between October 2016 and November 2016. Children received a thank-you gift for participating, and adults received course credit.

\section{Materials}

Materials were the same as those used in Study 1 with one exception - there was no plastic bag, as participants were required to distribute all the stickers to the friends.

\section{Design}

Participants heard the same third-party vignettes describing situations where friends offered no money (no money), equal amounts of money (one quarter each; equal money), or different amounts of money. As in Study 1, when offering different amounts of money, the following offers were made: (a) more/less: one friend offers two quarters, one friend offers one quarter, (b) refusal: one friend offers one quarter, one friend refuses to offer the one quarter they have available, and (c) inability: one friend offers one quarter, one friend offers zero quarters due to being unable to pay. Thus, participants heard five vignettes total. On every trial, participants were tasked with distributing five stickers. The no-money vignette was always presented first, and the other four vignettes were presented in randomized order.

\section{Procedure}

The procedure was the same as Study 1 with one exception-participants were told that the Giver could not keep any of the extra stickers for themselves; they could give them to both friends or to just one friend. As before, the arrangement of the bowls mirrored the spatial relation of the friends on the computer screen and children, for exploratory purposes, were asked why they distributed stickers the way they had after the last trial. Responses are not discussed further. The number of stickers distributed to each friend was recorded.

\section{Results}

To test our predictions, we first tallied the number of stickers distributed to each recipient (Friend A, Friend B). As before, when different offers were made, Friend A was defined as the friend who offered more money; when same offers were made, Friend A was simply defined as the friend on the left.

\section{Same Versus Different Offers}

In line with Study 1, we predicted that, given equity and market concerns, participants would distribute more stickers to Friend A than Friend B during different versus same trials. To test this, we calculated the proportion of stickers distributed to 
Friend A during same (no money, equal money) and different (more/less, refusal, inability) trials. As before, proportions were used to allow for comparison across the different numbers of trials (two same offer trials, three different offer trials). Values close to .50 indicate no preference, whereas values above .50 indicate a preference for Friend A. We conducted a repeated-measures ANOVA with offer type (same, different) as the within-participants factor and age group $(5-6,7-8,9-10$, adults) as the between-participants factor. This analysis yielded main effects of offer type, $F(1,150)=92.23$, $p<.001, \eta_{\mathrm{p}}^{2}=.38$, and age group, $F(3,150)=7.13$, $p<.001, \eta_{\mathrm{p}}^{2}=.13$, but no interaction. As in Study 1 , we set our alpha level to .0125 (i.e., .05/4) to account for multiple comparisons. Regardless of age, participants distributed more stickers to Friend A when offers were different (.66) than when they were the same (.51). However, children 5-6 years distributed fewer stickers to Friend A than children 7-8 years and adults (5-6: 0.53; 7-8: 0.59; 9-10: 0.58 ; adults: 0.63 ; $p \mathrm{~s} \leq .002$ ). See Figure 4 for distributions by offer type and age group.

Reanalysis of Study 1. The findings reported above are generally similar to those observed in Study 1 . Nonetheless, to enable a more direct comparison, we applied the analysis employed in Study 2 to the data from Study 1. That is, we calculated the proportion of stickers distributed to Friend A given the number of stickers distributed to both friends during each trial. We then conducted a repeated-measures ANOVA with offer type (same, different) and sticker number (Even, Odd) as the within-participants factors and age group (5-6, 7-8, 9-10, adults) as the between-participants factor. This analysis yielded main effects of offer type, $F$ $(1,97)=138.56, p<.001, \eta_{\mathrm{p}}^{2}=.59$, and age group, $F(3,97)=7.96, p<.001, \eta_{p}^{2}=.20$, and an Offer Type $\times$ Age Group interaction, $F(3,97)=3.09$, $p=.031, \eta_{p}^{2}=.09$. (Note that these effects are the same as those found in the original analysis of Study 1, indicating that the two different analytic methods yielded the same patterns.) As in Study 2, participants in Study 1 distributed more stickers to Friend A when offers were different (.61) than when they were the same (.48), and this trend was observed across all age groups even after setting our alpha level to .0125 to account for multiple comparisons $(p s<.001)$.

\section{No-Money Versus Equal Money Offers}

We next tested whether participants' distributions differed during same offers when money was involved versus not involved-again as a control to ensure that the inclusion of money per se did not unexpectedly influence behaviors. To do this, we tested whether the difference in the number of stickers distributed to the friends differed by vignette type. A repeated-measures ANOVA with vignette type (no money, equal money) as the within-participants factor and age group (5-6, 7-8, 9-10, adults) as the between-participants factor yielded no main effects nor an interaction. Thus,

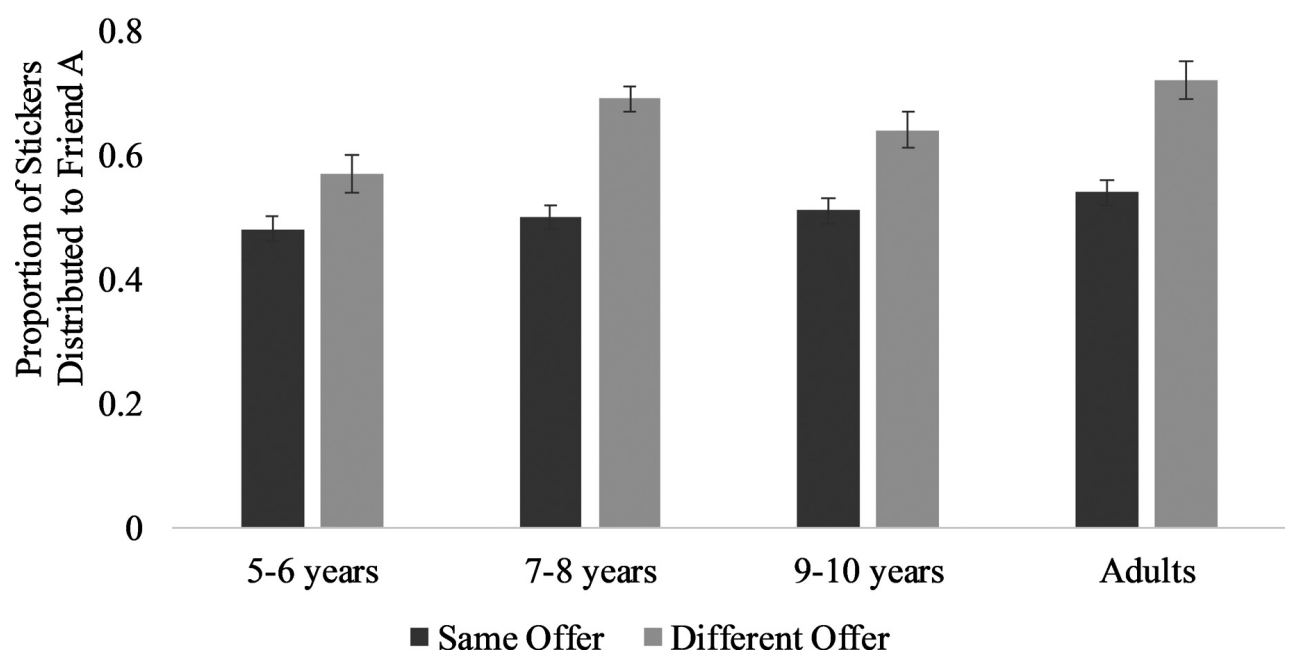

Figure 4. Proportion of stickers distributed to Friend A during Study 2. 
participants' distributions did not differ depending on whether money was involved.

\section{Different Offers: Equity Norms Versus Market Norms}

Turning to trials where different offers were made, we predicted, as before, that if strictly adhering to market norms, participants would distribute more stickers to Friend A than Friend B. However, appeals to equity norms would yield greater distributions to friends willing but unable to pay as compared with friends offering more or refusing to pay. As in Study 1, we tested this with a difference score (A-B). We conducted a repeated-measures ANOVA with vignette type (more/less, refusal, inability) as the within-participants factor and age group (5-6, $7-8,9-10$, adults) as the between-participants factor. This analysis yielded main effects of vignette type, $F(2,300)=11.12, p<.001, \eta_{p}^{2}=.07$, and age group, $F(3,150)=5.21, p=.002, \eta_{\mathrm{p}}^{2}=.09$, but no interaction. Setting our alpha level to .0125 to account for multiple comparisons, we found that the difference in the number of stickers distributed to the friends was greater during the refusal trial (1.81) than during both the more/less (1.10) and inability (0.88) trials ( $p$ s $\leq .002)$. Further, the difference in the number of stickers distributed to the friends by the youngest children (5-6 years) was smaller than the difference observed in children $7-8$ years and adults (5-6: 0.63; 7-8: 1.52; 9-10: 1.07; adults: 1.82; $p s \leq .005)$. See Figure 5 for distributions by vignette type and age group.
We next tested whether participants reliably distributed more stickers to the friend offering more money, testing participants' commitment to equity versus market norms. That is, we tested whether participants distributed significantly more stickers to Friend $A$ versus Friend $B$ than would be expected by chance (0; one-sample $t$-test; alpha not adjusted given independence of $t$-tests). Children $7-$ 10 and adults reliably distributed more stickers to Friend A during more/less (5-6: 0.71; 7-8: 1.33; 910: 0.89; adults: 1.46$)$ and refusal (5-6: 0.71; 7-8: 2.19; 9-10: 1.72; adults: 2.60 ) trials ( $p$ s < .001). However, only children $7-8$ years and adults reliably distributed more stickers to Friend A during inability trials (5-6: 0.46; 7-8: 1.05; 9-10: 0.61; adults: $1.40 ; p s<.01)$.

\section{Zero Offers: Market Norms Versus Equity Norms}

Finally, to test whether participants engaged in a pure-profit strategy, we tallied the number of trials on which participants (by age group) distributed zero stickers to friends offering less money during the more/less trial and no money during refusal and inability trials. As in Study 1, participants were more inclined to give nothing to the friend refusing to pay $(19.48 \%$ overall; $5-6: 7 / 41$ trials; $7-8: 12 / 42$ trials; 9-10: $4 / 36$ trials; adults: $7 / 35$ trials) versus the friends offering one fewer quarter $(6.49 \%$ overall; 5-6: 7/41 trials; 7-8: 3/42 trials; 9-10: 0/36 trials; adults: $0 / 35$ trials) and willing but unable to pay $(6.49 \%$ overall; $5-6: 2 / 41$ trials; $7-8:$ 6/42 trials;

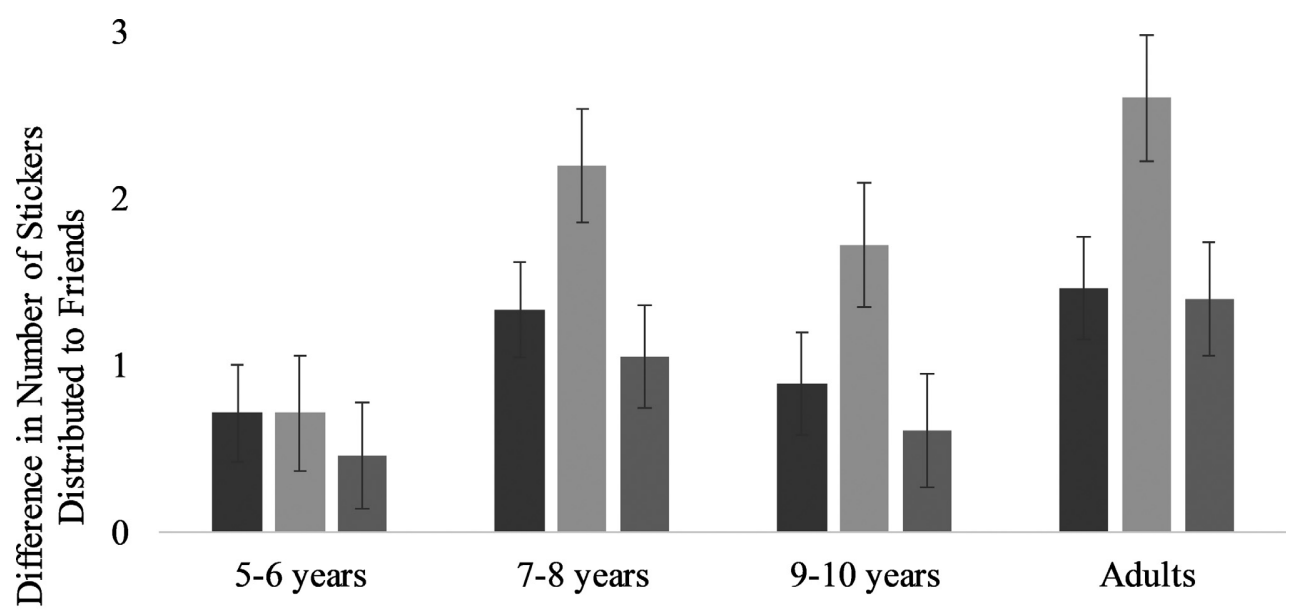

$-1$

- Pay More vs. Less $\quad$ Pay vs. Refuse to Pay $\quad$ Pay vs. Unable to Pay

Figure 5. Difference in the number of stickers distributed to friends (where positive numbers indicate a preference for the friend offering more) during Study 2. 
9-10: $2 / 36$ trials; adults: $0 / 35$ trials). Consistent with Study 1, participants' zero distributions did not differ by age group during any trial type, as assessed via logistic regressions where age group was entered as a categorical predictor and decision to give nothing versus at least one sticker was entered as the binary-dependent variable.

\section{Discussion}

Study 2 was designed to provide a stronger test of children's commitment to equal distributions by requiring participants to distribute an odd number of stickers between two friends. Consistent with the results from Study 1, including a re-analysis of Study 1 data using the Study 2 analysis, participants were more likely to distribute stickers unequally when different offers were made (assessed by determining whether there was a preference for Friend A over Friend B). Additionally, participants' distributions were sensitive to the distribution context, such that the difference in the number of stickers distributed to the friends was greater when someone refused to pay versus when someone was unable to pay or simply paid more (with no reason provided). This result is in line with those from Rizzo et al. (2016), where children 6- 8 years considered the welfare of the recipients when deciding how to distribute different kinds of resources. In addition, though participants rarely gave nothing to the friend offering no money, they were more inclined to do so when friends were refusing versus willing but unable to pay. Our results suggest that children were similarly sensitive to the welfare of the recipients, as those willing but unable to pay were given more stickers than those able but refusing to pay.

Although the difference in the number of stickers distributed to Friend A versus Friend B was greater during refusal than both more/less and inability trials, the differences in distributions to the two friends differed from zero for only older children and adults (though distributions for the youngest age group trended in the same direction for each condition). This last result demonstrates that children are willing to depart from equal distributions but increasingly so with age.

\section{General Discussion}

Across two studies, participants decided how a set of resources (extra stickers) should be distributed to two friends. In Study 1, participants distributed stickers with the possibility of reserving (not giving away) some, and in Study 2, participants distributed stickers exhaustively (all stickers given away). During each trial, friends offered the Giver either the same or different amounts of money and it was up to the participant to decide how the Giver should give away their extra stickers. In both studies, participants distributed stickers more equally when offers were the same and more unequally when offers were different. This is a novel finding, demonstrating that children as young as 5-6 years of age are willing to depart from equality when considering a person who offers more money. It is also consistent with prior work showing that children incorporate equity concerns (e.g., merit, need) into their distribution decisions. Last, it extends prior work on children's reciprocity by demonstrating that children are sensitive to relative quantity, such that those who offer more (money) receive more.

In addition to studying equality and equity norms, we examined the use of market norms, in which a person attempts to maximize monetary gains. The use of market norms would lead participants to select the friend who offers more money, regardless of other considerations (such as ability or willingness to pay). In the present study, older children and adults distributed more consistently based on market considerations than did younger children. The key test came on trials that pitted one person able to pay against another who was willing but unable to pay. Older participants gave fewer stickers to the person unable to pay. In contrast, younger children did not penalize partners who were willing but unable to pay: They received the same number of stickers as those who could (and did) pay. One way to interpret these results is that older participants relied on market norms even when those norms conflicted with equity (which would favor the person unable to pay). In contrast, younger participants relied on market norms when those norms did not obviously conflict with equity (no explanation or unwillingness to pay).

Despite overall very similar patterns across the two studies, participants' decreased attention to equity norms was found only in Study 1 and not in Study 2. We suspect that these study differences are due to one important methodological difference. Recall that in Study 2, it was simply not possible for participants to distribute equally on any trial, as they did in Study 1. As a consequence, participants who would otherwise have engaged in equal distributions were forced to shift their strategy, engaging in a "next-best" distribution strategy that was less 
consistent and more variable, introducing noise and yielding the different results. When equal distributions were possible (Study 1), the developmental patterns were clear. Overall, then, these results suggest that older children and adults may be less concerned about equity, strictly conceived, in these types of exchanges. In this way, results are consistent with our prediction that children, increasingly so with age, can entertain at least three types of norms when deciding how to distribute items in market-oriented exchanges.

The current study also extends research on children's sensitivity to reciprocity in exchanges. Previous research has shown that quite young children are more likely to give resources to others who have or will give them resources (e.g., Sebastián-Enesco \& Warneken, 2015; Warneken \& Tomasello, 2013). However, from that prior work it was not clear whether the amount given would be directly related to the amount received (or expected), as would be the case in more strictly market exchanges. In the current study, we found that even the youngest children did distribute more to those offering more. This consideration of quantity goes beyond a simple or informal construction of reciprocity. Older children and adults demonstrated an even stricter form of market norms: The amount given depends only on the amount offered not the reasons behind the offer. Specifically, in the case of the friend willing but unable to pay, general reciprocity would favor giving. That friend may be able to reciprocate, perhaps nonmonetarily, in the future.

In light of support for this last prediction, we argue that young children do follow market norms when distributing or exchanging resources, at least in addition to norms of equality and equity. One of the claims of this paper is that market norms function as a specific form of reciprocity that regulates exchanges. In the present studies, market exchanges were evoked by including money in the exchange contexts - though, we acknowledge that not all market exchanges involve money (e.g., barter systems), nor is it the case that market exchanges require money. For this reason, observed trends may not extend to children outside our WEIRD (western, educated, industrialized, rich, and democratic) samples (e.g., consider that Blake and colleagues found clear developmental differences in the rejection of disadvantageous inequity across different cultures, demonstrating the importance of context in examining these issues; Blake et al., 2015). An alternative perspective, however, is that equality and equity are not distinct norms but rather distinct aspects or varieties of market considerations. From an economic perspective, all exchanges are based on expected utility: The person making the offer is maximizing some return. The return may be material (the amount of goods received) or immaterial (friendship, goodwill, or indebtedness of the recipient). The return may also be quite abstract, as in a sense of justice being done, or a "warm-glow" from having done the right thing (Andreoni, 1990). Equality and equity are just different kinds of utilities to be maximized. We do not take a position on the nature of equality and equity motivations nor on whether such norms are fundamentally different from utility maximization. However, one key feature of money is that it is quantifiable. Money provides a common medium in which different values can be expressed. Therefore, monetary exchanges may be most suited to the application of market norms that depend on specific assessment of quantities (values) exchanged. The current study demonstrates that young children do consider the specific amounts of goods and money offered in exchange, at least in addition to more abstract goals of equality and equity. Older children and adults privilege the linkage between amounts offered in exchange above equality and equity, at least in this cultural context and this specific context of exchanging goods for money. Recognizing that it is right or appropriate to do so (in the context of exchanging goods for money) is what we take to be the market norm.

The current study used money as the medium of exchange. Previous literature suggests that the inclusion of money may prompt children to adopt a more market-oriented perspective (Gasiorowska, Chaplin, Zaleskiewicz, Wygrab, \& Vohs, 2016; Gasiorowska, Zaleskiewicz, \& Wygrab, 2012). Contrary to this prediction, we did not find that distribution decisions differed when comparing no money and equal money trials. However, our studies were not designed to test the effects of money per se, and future work should test whether the same results would be observed with other, nonmonetary forms of exchange (e.g., bartering).

In addition, the transactions in the current study were introduced as exchanges among friends, leaving open how children would distribute resources in the context of strangers or family members (Olson \& Spelke, 2008). The use of friends may have reduced market norms and increased concerns with equality and equity, so it is all the more interesting that even the youngest children adopted market norms to guide their distribution decisions in the context of friends. Perhaps asking children to distribute among strangers would amplify effects of market norms, or asking children to distribute 
among family members would decrease their effects. Importantly, though, using a third-party design limits selfish interests that participants could bring to bear on the task-yielding results that can more clearly speak to whether and when participants adhere to different norms. However, a firstparty design (one where a child would be a direct stakeholder) would provide insight into how children balance personal interests with concerns over equality, equity, and maximizing returns. Another aspect of the task framing was that distributions did not involve a store context, which is the most familiar place where market norms apply. It is an open question whether we would observe similar results in more market-oriented contexts (e.g., a store). Though these open questions remain, it is nonetheless interesting that children appealed to market norms in this market exchange context involving friends, outside a context that would more clearly dictate distributing based on ability to pay as would be the case in a store. Last, subsequent work should explore whether children explicitly reference market concerns when participating in a market exchange. It could be that children display market-oriented behaviors but motivate decisions appealing to fairness norms - a finding that would inform how children balance multiple concerns simultaneously.

\section{Conclusions}

In line with prior work exploring children's attention to equity concerns when distributing items, we found that children as young as 56 years will depart from equality and use money offers to guide their distribution decisions. In addition, we found that children are sensitive to the reasons underlying the different offers - that is, children penalize recipients refusing to pay more than recipients willing but unable to pay. Last, participants did not adhere to a pure-profit strategyparticipants still distributed stickers to friends offering no money or lesser amounts of money. Taken together, these studies contribute to our understanding of factors influencing children's distribution decisions with the novel finding that children as young as 5-6 years will consider money offers and depart from equal distributions.

\section{References}

Andreoni, J. (1990). Impure altruism and donations to public goods: A theory of warm-glow giving. The
Economic Journal, 100, 464-477. https://doi.org/10. $2307 / 2234133$

Baumard, N., Mascaro, O., \& Chevallier, C. (2012). Preschoolers are able to take merit into account when distributing goods. Developmental Psychology, 48, 492498. https://doi.org/10.1037/a0026598

Blake, P. R., McAuliffe, K., Corbit, J., Callaghan, T. C., Barry, O., Kleutsch, L., . . . Warneken, F. (2015). The ontogeny of fairness in seven societies. Nature, 528, 258-262. https:// doi.org/10.1038/nature15703

Carrell, M. R., \& Dittrich, J. E. (1978). Equity theory: The recent literature, methodological considerations, and new directions. Academy of Management Review, 3, 202 210. https://doi.org/10.5465/AMR.1978.4294844

Chernyak, N., \& Sobel, D. M. (2016). Equal but not always fair: Value-laden sharing in preschool-aged children. Social Development, 25, 340-351. https://doi.org/ 10.1111/sode.12136

Deutsch, M. (1975). Equity, equality, and need: What determines which value will be used as the basis of distributive justice? Journal of Social Issues, 31, 137-149. https://doi.org/10.1111/j.1540-4560.1975.tb01000.x

Dunfield, K. A., Kuhlmeier, V. A., \& Murphy, L. (2013). Children's use of communicative intent in the selection of cooperative partners. PLoS ONE, 8, e61804. https://doi.org/10.1371/journal.pone.0061804

Elenbaas, L., \& Killen, M. (2016). Children rectify inequalities for disadvantaged groups. Developmental Psychology, 52, 1318-1329. https://doi.org/10.1037/dev0000154

Elenbaas, L., Rizzo, M. T., Cooley, S., \& Killen, M. (2016). Rectifying social inequalities in a resource allocation task. Cognition, 155, 176-187. https://doi.org/10.1016/ j.cognition.2016.07.002

Fiske, A. P. (1991). Structures of social life: The four elementary forms of human relations: Communal sharing, authority ranking, equality matching, market pricing. New York, NY: Free Press.

Gasiorowska, A., Chaplin, L. N., Zaleskiewicz, T., Wygrab, S., \& Vohs, K. D. (2016). Money cues increase agency and decrease prosociality among children: Early signs of market-mode behaviors. Psychological Science, 27, 331344. https://doi.org/10.1177/0956797615620378

Gasiorowska, A., Zaleskiewicz, T., \& Wygrab, S. (2012). Would you do something for me? The effects of money activation on social preferences and social behavior in young children. Journal of Economic Psychology, 33, 603608. https://doi.org/10.1016/j.joep.2011.11.007

Hamann, K., Bender, J., \& Tomasello, M. (2014). Meritocratic sharing is based on collaboration in 3-year-olds. Developmental Psychology, 50, 121-128. https://doi.org/ $10.1037 / \mathrm{a} 0032965$

Heyman, J., \& Ariely, D. (2004). Effort for payment a tale of two markets. Psychological Science, 15, 787-793. https://doi.org/10.1111/j.0956-7976.2004.00757.x

House, B., Henrich, J., Sarnecka, B., \& Silk, J. B. (2013). The development of contingent reciprocity in children. Evolution and Human Behavior, 34, 86-93. https://doi. org/10.1016/j.evolhumbehav.2012.10.001 
Kanngiesser, P., \& Warneken, F. (2012). Young children consider merit when sharing resources with others. PLoS ONE, 7, e43979. https://doi.org/10.1371/journal. pone.0043979

Kenward, B., \& Dahl, M. (2011). Preschoolers distribute scarce resources according to the moral valence of recipients' previous actions. Developmental Psychology, 47, 1054-1064. https:/ / doi.org/10.1037/a0023869

Olson, K. R., \& Spelke, E. S. (2008). Foundations of cooperation in young children. Cognition, 108, 222-231. https: / / doi.org/10.1016/j.cognition.2007.12.003

Rizzo, M. T., Elenbaas, L., Cooley, S., \& Killen, M. (2016). Children's recognition of fairness and others' welfare in a resource allocation task: Age related changes. Developmental Psychology, 52, 1307-1317. https://doi.org/10. $1037 / \operatorname{dev} 0000134$

Rizzo, M. T., \& Killen, M. (2016). Children's understanding of equity in the context of inequality. British Journal of Developmental Psychology, 34, 569-581. https://doi. org/10.1111/bjdp.12150

Romo, L. K. (2011). Money talks: Revealing and concealing financial information in families. Journal of Family Communication, 11, 264-281. https://doi.org/10.1080/ 15267431.2010.544634

Schmidt, M. F., Svetlova, M., Johe, J., \& Tomasello, M. (2016). Children's developing understanding of legitimate reasons for allocating resources unequally.
Cognitive Development, 37, 42-52. https://doi.org/10. 1016/j.cogdev.2015.11.001

Sebastián-Enesco, C., \& Warneken, F. (2015). The shadow of the future: 5-year-olds, but not 3-year-olds, adjust their sharing in anticipation of reciprocation. Journal of Experimental Child Psychology, 129, 40-54. https://doi. org/10.1016/j.jecp.2014.08.007

Shaw, A., \& Olson, K. R. (2012). Children discard a resource to avoid inequity. Journal of Experimental Psychology: General, 141, 382-395. https://doi.org/10.1037/ a0025907

Siegler, R. S., \& Thompson, D. R. (1998). "Hey, would you like a nice cold cup of lemonade on this hot day?": Children's understanding of economic causation. Developmental Psychology, 34, 146-160. https://doi.org/10. 1037/0012-1649.34.1.146

Sloane, S., Baillargeon, R., \& Premack, D. (2012). Do infants have a sense of fairness? Psychological Science, 23, 196204. https:/ / doi.org/10.1177/0956797611422072

Tetlock, P. E. (2003). Thinking the unthinkable. Sacred values and taboo cognitions. Trends in Cognitive Sciences, 7, 320-324. https://doi.org/10.1016/S13646613(03)00135-9

Warneken, F., \& Tomasello, M. (2013). The emergence of contingent reciprocity in young children. Journal of Experimental Child Psychology, 116, 338-350. https://doi. org/10.1016/j.jecp.2013.06.002 